\title{
Successful shuttle avoidance learning with high- intensity USs is sustained if a feedback signal accompanies warning-signal termination
}

\author{
GEORGE A. CICALA and JOHN W. OWEN \\ University of Delaware, Newark, Delaware 19711 \\ and \\ DENEICE HILL \\ University of Maryland, College Park, Maryland 20740
}

\begin{abstract}
The inverse relation between US intensity and shuttle avoidance performance has been consistently demonstrated when warning-signal termination (WST) is response contingent. The more recent demonstration that a feedback signal (FS) can effectively replace WST during acquisition, and the discovery that acquisition is most rapid when an FS and WST are correlated stimulus events, prompted the present experiment. The reinforcing effectiveness of three feedback conditions, WST, an FS, and both events combined, was assessed for three different shock levels. The results indicated that when either WST or an FS was response contingent, avoidance responding was inversely related to US intensity. When WST and FS onset were correlated, avoidance responding was unaffected by increases in US intensity. These results support a position that WST and an FS reinforce through different mechanisms whose reinforcing effects summate when both events occur together.
\end{abstract}

By now it is well known that a feedback signal (FS) can effectively replace warning-signal termination (WST) in the shuttle avoidance situation (Bower, Starr, \& Lazarovitz, 1965; Bolles \& Grossen, 1969). Bolles and Grossen have chosen to interpret the interchangeability of these stimulus events as supporting the view that they serve identical reinforcing functions. Recently, however, Cicala and Owen (in press) discovered a number of situations in which the FS was a consistently less effective reinforcer of avoidance responding than was WST. They interpreted this to mean that these two stimulus events provide different forms of reinforcement. Specifically, they suggested that avoidance learning is reinforced by fear reduction and that WST permits fear to dissipate while the FS produces Pavlovian inhibition of fear. The attractiveness of this interpretation is enhanced by the fact that it predicts a greater reinforcement of avoidance responding when WST and an FS are both made response contingent, a result which is frequently obtained (Bolles \& Grossen 1969; Cicala \& Owen, in press).

Another consistent finding in shuttle avoidance learning is the inverse relation between US intensity and the facility with which the shuttle avoidance response is acquired (cf. Theios, Lynch, \& Lowe, 1966). McAllister, McAllister, and Douglas (1971) have interpreted this phenomenon in terms of the failure of WST to provide sufficient fear reduction when high intensities of shock are used. While this may be the case, it is yet to be demonstrated that the reinforcing effectiveness of an FS also diminishes when high-intensity USs are employed.
The purpose of the present experiment was to explore this possibility and, further, to determine if the combination of WST and an FS is sufficient reinforcement to sustain avoidance learning with a high-intensity US.

\section{METHOD}

\section{Subjects}

The subjects for this experiment were 90 male Wistar rats weighing about $250 \mathrm{~g}$.

\section{Apparatus}

The apparatus was a shuttlebox $40 \mathrm{~cm}$ long, $17.5 \mathrm{~cm}$ wide, and $17.5 \mathrm{~cm}$ high. The walls were of aluminum and the top of Plexiglas. The grid floor was constructed of $.23-\mathrm{cm}$ steel rods on $1.25-\mathrm{cm}$ centers. Each half of the shuttlebox floor was a separately mounted section connected to a mercury switch. This allowed the electromechanical programming equipment to monitor which side of the apparatus the rat was on. A 6-W lamp and a $20-\mathrm{cm}$ speaker were each centrally located $27.5 \mathrm{~cm}$ above the shuttlebox. The entire shuttle apparatus was contained in a sound-attenuating enclosure.

The WS was white noise delivered to the speaker from a Grason-Stadler Model 901 noise generator. Presentation of the WS increased the average ambient sound level of $37.5 \mathrm{~dB}$ to 81 dB. The US was scrambled ac shock from a $150 \mathrm{~K} \Omega$ fixedimpedance source (Campbell \& Masterson, 1969). A Gerbrands cumulative recorder monitored stimulus events from which escape and avoidance behavior could be determined.

\section{Procedure}

The 90 subjects were divided into nine equal groups which were treated differently with respect to type of responsecontingent feedback and intensity of the US. These were varied so as to yield a 3 by 3 factoral design. All subjects received 100 trials of shuttle avoidance acquisition with a 10-sec WS-US 
interval and a 35 -sec ITI. Rats in the WST (T) condition received immediate WST following each escape and avoidance response. For subjects in the FS (F) condition, each response produced a 10 -sec FS and a 10-sec delay in WST. Subjects in the combined (TF) condition received immediate WST and a 10-sec FS. Within each condition, one group was trained at $90 \mathrm{~V}$, one group was trained at $135 \mathrm{~V}$, and one group was trained at $180 \mathrm{~V}$. In all cases, the FS was produced by extinguishing the houselight.

\section{RESULTS AND DISCUSSION}

The results of this experiment are presented in Figure 1 , which shows mean percent avoidance as a function of US intensity. It can be seen from this figure that for subjects in the $\mathrm{T}$ condition and the $\mathrm{F}$ condition, performance deficits accompanied US increases. The trend was not as pronounced in the TF condition, which was more resistant to the detrimental influence of high shock level.

A 3 by 3 by 10 analysis of variance was performed on the number of avoidances in each block of 10 trials. The results indicated a significant effect for type of response feedback $[F(2,81)=26.92, p<.001]$, US intensity $[F(2,81)=16.59, \quad \mathrm{p}<.001]$, and the interaction $[F(4,81)=3.92, p<.006]$. A subsequent NewmanKeuls test revealed that groups $T_{135}, T_{180}$, and $F_{180}$, performed at lower levels than the other six groups.

The data clearly demonstrate that when either an FS or WST is made contingent upon escape and avoidance responding, their reinforcing properties are affected similarly by increasing US intensity. The general features of the data suggest an inverse relation between US intensity and avoidance acquisition when either WST or an FS is made response contingent. It appears safe to assume that these stimulus events are less reinforcing when avoidance learning is motivated by more intense shock. If it is assumed, as we have done previously, that WS is a fear-eliciting stimulus gaining its excitatory properties through Pavlovian conditioning and that

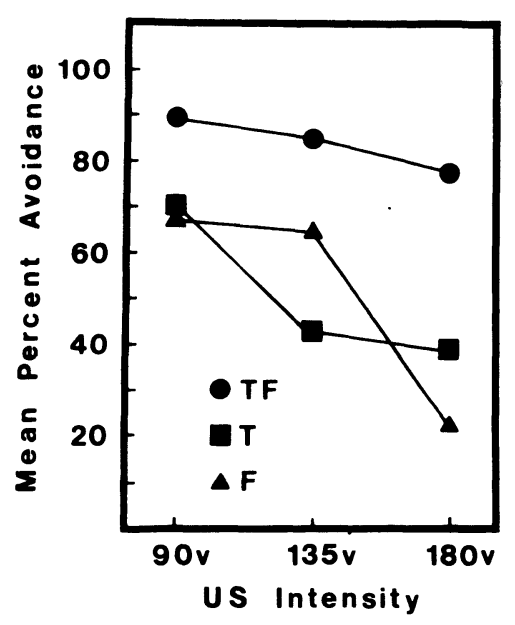

Figure 1. Mean percent avoidance as a function of US intensity. Groups received either a feedback signal (F), immediate WS termination (T), or both events (TF). avoidance responding is reinforced by fear dissipation when WST is response contingent and by Pavlovian fear inhibition when an FS is response contingent, the data would suggest that the fear-reducing properties of these stimulus events diminish when WS fear is intensified. If the FS and WST operations are assumed to equally reduce WS-produced fear, it follows that they would reinforce equally at all US intensities. The data from the present experiment suggest that they are equal, and therefore interchangeable, reinforcing events only for the highest and lowest intensities studied. The comparison between the $\mathrm{T}$ and $\mathrm{F}$ groups at $135 \mathrm{~V}$ suggests that this analysis is too simple. For this intensity, the FS was more reinforcing than WST. It is tempting to ignore this difference since neither we nor anyone else, to our knowledge, has found an FS to produce superior avoidance to WST. It is no doubt possible to construct a model which assumes a complex interaction between WS-produced fear and FS-produced inhibition, but at this time such speculation appears premature.

The data also, and perhaps more importantly, provide strong evidence for the contention that an FS and WST are not functionally identical. Avoidance learning was sustained at a high level regardless of US intensity when WST and an FS were both made response contingent. These results suggest that these stimulus operations in combination more effectively reinforce avoidance learning than when either occurs alone. It seems simplest to explain this result by postulating that an FS and WST serve different fear-reducing functions. Thus with low levels of WS fear produced by low-intensity USs, either an FS, WST, or the two events in combination can produce sizable decrements in fear and cause rapid avoidance learning. With high-intensity USs, neither an FS nor WST produces sufficient fear reduction to sustain avoidance responding while the fear-reducing effects of both stimulus events in combination summate to reinforce effectively the avoidance response.

\section{REFERENCES}

Bolles, R. C., \& Grossen, N. E. Effects of an informational stimulus on the acquisition of avoidance behavior in rats. Journal of Comparative and Physiological Psychology, 1969, 68, 90-99.

Bower, G., Starr, R., \& Lazarovitz, L. Amount of responseproduced change in the CS and avoidance learning. Journal of Comparative and Physiological Psychology, 1965, 59, 13-17.

Campbell, B. A., \& Masterson, F. A. Psychophysics of punishment. In B. A. Campbell \& R. M. Church (Eds.), Punishment and Aversive Behavior. New York: AppletonCentury-Crofts, 1969.

Cicala, G. A. \& Owen, J. W. Warning signal termination and a feedback signal may not serve the same function. Learning and Motivation, in press. 
McAlister, W. R., McAllister, D. E. \& Douglass, W. K. The inverse relationship between shock intensity and shuttlebox avoidance learning in rats: A reinforcement explanation. Journal of Comparative and Physiological Psychology, 1971, 74, 426-433.

Theios, J., Lynch, A. D., \& Lowe, W. F., JR. Differential effects of shock intensity on one-way and shuttle avoidance conditioning. Journal of Experimental Psychology, 1966, 72, 294-299.

(Received for publication February 26, 1976.) 